\title{
Гужевая транспортировка судостроительной древесины в эпоху парусного флота в России
}

\author{
Лупанова Е.М. \\ Музей антропологии и этнографии им. Петра Великого РАН (Кунсткамера), \\ Россия, 199034, Санкт-Петербург, Университетская наб., д. 3 \\ E-mail: lupanova@kunstkamera.ru
}

\begin{abstract}
Аннотация. Статья посвящена неисследованным аспектам техники перевозок лесоматериалов с места заготовления к верфям. В XVIII - первой половине XIX в. такие работы имели военностратегическое значение - от их качества зависело состояние и боеспособность судов парусного флота. На берегах сплавных рек ресурсы были быстро исчерпаны и материалы стали доставляться к водным коммуникациям гужевым транспортом. История этих масштабных перевозок до сих пор оставалась за рамками исследовательского внимания. Одним из важных вопросов является количество лошадей, требовавшихся для гужевой транспортировки. Современные гужевые перевозки используются для существенно меньших грузов. Сопоставимые с перевозками материалов для строительства парусных кораблей осуществляются исключительно при помощи техники.
\end{abstract}

Ключевые слова: парусный флот, транспортировка лесоматериалов, гужевой транспорт, тяжеловоз, зимние работы.

Для цитирования: Лупанова Е.М. Гужевая транспортировка судостроительной древесины в эпоху парусного флота в России. Via in tempore. История Политология. 48 (3): 653-660. DOI 10.52575/2687-0967-2021-48-3-653-660.

\section{Horse-drawn transportation of the ship-building wood during the period of sailing navy in Russia}

\author{
Yevgenia M. Lupanova \\ Peter the Great's museum for anthropology and ethnography RAS (Kunstkamera), \\ 3 University Emb., Saint Petersburg, Russia, 199034 \\ E-mail: lupanova@kunstkamera.ru
}

\begin{abstract}
The article is devoted to some aspects of the technique of wood transportation. This kind of work were especially important during the period of sailing navies, when the qualities of ships depended on the quality of wood. Most oak wood for Russian navy was brought from the Middle Volga region. The Volga was the main river of that transportation, but the resources on its banks were quickly exhausted. Most proper woods grew quite far from it and had to be delivered first by smaller rivers and horses. This technique had not been researched yet. There are two different evidences on the amount of horses needed for pulling wood. The thesis of the article is the sure number, which cannot be inferred from still existing practice because commensurable heavy loads have been transported mechanically only during last several decades. The other theses are - special breeds of draught horses, mainly the winter season of land transportation and high costs according more for a big state great imperial projects then private businessmen.
\end{abstract}

Key words: sailing navy, wood transportation, horse drawing, breeding draught horses, winter works.

For citation: Lupanova Ye.M. Horse-drawn transportation of the ship-building wood during the period of sailing navy in Russia. Via in tempore. History and political science. 48 (3): 653-660 (in Russian). DOI 10.52575/2687-0967-2021-48-3-653-660. 


\section{Введение}

Работы по заготовке и транспортировке древесины в эпоху парусного флота играли существенную роль в обеспечении каждого нового навигационного сезона, и потому они имели государственное военно-стратегическое значение. Срок жизни парусных кораблей был коротким. При удачном стечении обстоятельств (корабль не попадал в серьезные штормы, не получал повреждений в сражениях) - 10 лет, лишь в исключительных случаях можно было видеть корабли, остававшиеся на плаву после 20 лет службы на море. Иногда корпуса начинали течь в первое же лето на море. Особенно острой проблема быстрого выхода судов из строя стала в первые десятилетия существования Черноморского флота [Гребенщикова, 2004]. Военный парусный флот требовал постоянного ремонта и обновления судового состава. Эта потребность влекла за собой ежегодные масштабные лесозаготовки. Требования к доставляемым на верфи материалам предъявлялись высокие. Ресурсы такой древесины - здоровые 100-200-летние дубы и безупречно прямые сосны - были исчерпаны уже в первые годы строительства регулярного флота, и в последующие десятилетия первым этапом транспортировки была доставка до сплавной реки, притом это расстояние постоянно увеличивалось по мере дальнейшего истощения. Соответственно, возрастала и роль гужевых перевозок.

В условиях пока еще относительно слабо развитого рынка значение этого процесса было в гораздо большей степени связано со становлением России как морской империи и с сохранением этого высокого статуса на международной арене, чем с интенсификацией торговли.

В данной статье будет рассмотрен этот до сих пор остававшийся за рамками исследовательского внимания вопрос. Нельзя назвать историю гужевого транспорта вопросом, не получившим разработки в историографии, но историки чаще обращают внимание на пассажирские перевозки и относительно небольшие грузовые [Гольц, 2007; Сидякина, 2015; Трошина, 2015; Журин, 2018; Конорев, Щерба, 2018; Логинова, 2020]. Транспортировка корабельной древесины - перемещение огромных тяжелых грузов - своеобразный вызов технологиям XVIII в. Едва ли какие-либо другие цели строительства или торговли требовали поиска и мобилизации таких мощностей, их постоянного роста и развития.

Гужевые перевозки в прямом и в переносном смысле ложились всей своей тяжестью на плечи податного населения. Вопросы технической реализации замыслов строительства флота на этом этапе не волновали ни столичных чиновников, ни умы академических ученых. Решение технических вопросов на уровне исполнителей обуславливает слабость источниковой базы. Проблема едва ли могла найти отражение в инструкциях и документах делопроизводства. Лишь в качестве исключения из правил можно рассматривать представленный на рассмотрение Вольного экономического общества проект конструкции из катков для перевоза бревен ${ }^{145}$. Приходится смириться с тем, что произведения художественной литературы являются едва ли не единственным возможным письменным источником для изучения вопроса. Это обстоятельство признавал еще М.А. Цейтлин, один из авторитетнейших советских специалистов в области истории российского лесного хозяйства.

Однако литературные источники противоречивы. В «Записках жандармского штабофицера о эпохе Николая I» упоминается сухопутная перевозка: «... чтобы вывезти дуб на пристань, в особые для того сани запрягают до 150 лошадей. Двинуть с места мало 200 человек, и бьются не один день...» [Стогов, 2003, с. 144]. Можно ли себе представить сани, запряженные 150 лошадьми? В интернете нетрудно найти фотографии американских

145 Перевод с немецкого, содержащий объяснение модели, присланный Вольному экономическому обществу от г. Миллера. 14 мая 1804 г. // РГИА. Ф. 91. Вольное экономическое общество. Оп. 1. Д. 461. Проекты, записки и письма разных лиц о проведении опытов по выращиванию различных земледельческих культур, предотвращении падежа скота, лечения зубов, об изменении порядка рекрутских наборов, о возделывании пустошей и увеличении лесонасаждений с чертежами и рисунками. 1803-1806 гг. Л. 69-70. 
лесозаготовок конца XIX - начала XX в. ${ }^{146}$ Груженые бревнами и запряженные 2-4 лошадьми сани производят впечатление. Фантазии едва хватает увеличить груз и количество лошадей в 2-3 раза.

М.А. Цейтлин писал, что на перевозе древесины с мест рубки лошади редко выдерживали больше года. Его данные существенно отличаются от процитированных выше воспоминаний Э.И. Стогова - в сани запрягали от 10 до 25 лошадей [Цейтлин, 1951, c. 118].

При столь значительной разнице в цифрах следует разобраться в достоверности данных. Для полноты картины следует рассмотреть средства гужевой перевозки и ее сезонный характер.

\section{Объекты и методы исследования}

Объектами исследования являются технологии гужевой транспортировки лесоматериалов в России периода парусного флота.

Статья написана в русле технологической истории, одной из основных идей которых является мысль о том, что технологии во многом определяют возможности развития производства, торговли, армии и соответственно - экономики страны и социальнополитических отношений.

Технологии заготовки и транспортировки лесоматериалов имели стратегическое значение для положения стран на международной арене в эпоху парусного флота - качество древесины определяло качество военных кораблей; мощный морской флот, в свою очередь, был залогом авторитета державы.

Методология технологической истории была сформулирована и опробована в американской историографии, получила дальнейшее развитие на материалах всего мира. В рамках этой концепции культурная история, социально-экономические процессы, история науки и знаний и многое другое объясняются технологическими новациями [Brush, 1988; Pursell, 1995; Hård, Jamison, 1998]. Такой взгляд по своей сути имеет общее с теорией К. Маркса и Ф. Энгельса о производительных силах как важнейшем факторе исторического процесса [Маркс, Энгельс, 1959], соответственно, различные технологические процессы неизменно привлекали к себе внимание советских историков.

\section{Результаты и их обсуждение}

Рубка и вывоз древесины к сплавным рекам относились к зимним сезонным работам. Труд на лесозаготовках был тяжелым и изнурительным и для людей, и для лошадей.

Для решения поставленного во вводной части статьи вопроса о количестве лошадей, требовавшихся для перевоза лесоматериалов, рассчитаем массу 300-летнего дуба, принимая за средние габариты высоту 30-40 м и диаметр ствола 1,5 м ${ }^{147}$. Объем ствола получится равным 53-70 кубометрам. При средней плотности дуба 750 кг/м ${ }^{3}$ масса ствола должна составлять порядка 40-50 тонн. Историк Ф.Г. Ислаев пишет о заготовке восьмиметровых дубов и норме вывозки 15-18 пуд (т. е. до 295 кг) на 25 вёрст на каждого конного рабочего, отмечая невыполнимость этих требований [Ислаев, 2018, с. 108]. Представляется, что в использованных им источниках речь шла о среднем распределении нагрузки. Иначе получается, что вывозили очень тонкие жерди или бревна, разрубленные на куски меньше половины кубометра каждый.

Что касается непосильности, одна лошадь при нормальной (не экстремальной, приводящей к перенапряжению животного) нагрузке может тащить на санях до 2 т груза, тя-

146 Архивные фотографии рабочих пошадей прошлого.

http://anub.ru/29.11.2013/arhivnie_fotografii_rabochih_loshadey_proshlogo/ (дата обращения 22.04.2021).

147 Размеры дуба. - URL: https://razmery.info/priroda/razmery-duba.html (дата обращения 22.04.2021). 
желовоз - до 9-10 т, известны случаи еще большей выносливости. Если 40-50 тонн разделить на 2, то получится, что нужно запрячь в сани 20-25 лошадей; или разделить на 10, и получится 4-5 тяжеловозов [Карлсен, 1951]. Это количество могло быть уменьшено в условиях нехватки лошадей, превышении нормальной нагрузки и создании экстремальной - вспомним слова о коротком веке лошадей на таких работах. Следовательно, данные М.А. Цейтлина, хоть и основаны на литературных источниках, являются достоверными, а для воспоминаний Э.И. Стогова характерно художественное преувеличение.

Попутно стоит отметить, что преувеличение «отягощений и разорений» были в не меньшей степени свойственны обращением лесозаготовителей к власти - обычно их целью было снижение нагрузки. Эти документы соответствовали установке марксистской историографии об «эксплуатации трудящихся» и «угнетения нерусских народов» «нарождавшейся капиталистической верхушкой». Сетования на жизнь перекочевали на страницы исторических исследований и по сей день остаются довольно устойчивой традицией. Свидетельствами тому являются не только работы упомянутого уже автора [Ногманов, 2008; Мансурова, 2010; Гафаров, 2018; Демидов, 2018]. Данный тезис нуждается в пересмотре. Вопросы, связанные с тяготами и лишениями людей, занятых на лесозаготовках, будут рассмотрены в одной из следующих публикаций. В данной же публикации уместно сказать о тащивших бревна лошадях.

История русского флота начиналась на Дону, в Воронеже и его окрестностях. В 1701 г. для развития судостроения туда было переселено около тысячи крестьянских дворов. Эти хозяйства следовало обеспечить лошадьми-тяжеловозами. Петр I приказал отправить из Скопинского дворцового завода в Рязанской губернии 63 «кобылиц и жеребцов», среди которых были лошади гольштинские, мекленбургские, неаполитанские, датские, голландские (из перечисленных особенно важно было наличие голландских тяжеловозов). Они должны были дать потомство вместе с прибывшими немногим ранее лошадьми, многие из которых уже были облагорожены датско-голландской кровью, так как переселенцы выбирались из заводских слобод придворных конюшен. Богатые травами пастбища окрестностей Воронежа в совокупности с селекцией наиболее сильных и выносливых животных стали условиями появления особой породы тяжеловозов - битюгов, активно использовавшихся на лесозаготовках в течение всего рассматриваемого периода [Дубенский, 1896; Кечеджи-Шаповалов, 1912].

Гужевые работы преимущественно носили сезонный характер. Большая их часть производилась зимой, на санях, по хорошему слою снега. Каждый ствол старались начать перевозить к реке сразу после валки и обрубки ветвей и суков. Так как рыхлый снег не может долго держать бревно (оно начинает проваливаться, кроме того, его может замести свежим снегом), перевозку спешили осуществить без остановок, перепрягая лошадей на ходу [Цейтлин, 1951, с. 118].

Летом объемы транспортировок были существенно ниже. Их осуществляли при помощи волоков - среди буреломов и болот они были значительно практичнее колес. Волоки представляли собой оглобли, «которых верхних концы также запрягаются посредством дуг, а нижние, имея вид клюки, соединены между собою довольно толстою подушкою, или попереченою, чтоб могла выдержать тяжесть бревна». Волоки делали из елей. Перед транспортировкой вершину бревна обтесывали и захватывали цепью, «которой один конец прикреплен к поперечине, соединяющей оглобли вышеупомянутой подушки», в волоки запрягали лошадей и тащили бревно к реке по заранее подготовленной дороге [Цейтлин, 1940, с. 66].

В целом чем дольше был гужевой перевоз, тем дороже стоили материалы [Гильдеман, 1836; Кувалдин, 1952; Истомина, 1982]. Путь до сплавной реки и перевоз по суше между реками был самой трудоемкой частью транспортировки. Дальность сухопутных перевозок определяла зоны правительственной охраны лесов - леса, расположенные далеко от рек, не подлежали охране. Дороговизна гужа предопределяла низкие коммерческие 
выгоды. Гуж был приемлем для амбициозных имперских проектов, но купцам зачастую был невыгоден. Яркий пример тому приводит А.А. Фет в очерке «Из деревни»: «в Орле пуд ржи с небольшим 30 к., в Москве 40 к. Доставка до Москвы с небольшим 60 к. за пуд. Следовательно, мне почти вдвое выгоднее сжечь свою рожь на месте, чем тащить ее гужом в Москву» [Фет, 1863].

\section{Выводы}

Для гужевой доставки заготовленных лесоматериалов к сплавным рекам в сани запрягали до 20-25 простых лошадей или 4-5 тяжеловозов.

При сухопутных перевозках лесоматериалов для строительства регулярного военно-морского флота была выведена особая порода лошадей - битюги, произошедшие от скрещивания голландских тяжеловозов с русскими в условиях обильных пастбищ и целенаправленного отбора наиболее приспособленных к тяжелому труду животных.

Гужевые перевозки имели сезонный характер, осуществлялись зимой, были самым тяжелым и дорогостоящим этапом заготовки и транспортировки материалов для строительства кораблей.

\section{Список литературы}

1. Гафаров И.А. 2018. «Корабельная» повинность лашманов Буинского уезда в XVIII первой половине XIX века: некоторые штрихи. Казанское адмиралтейство (1718-1830 гг.): народы Поволжья и традиции российского судостроения. Казань: Институт истории им. Ш. Марджани АН PT: 51-62.

2. Гильдеман Г. 1836. О доставке леса сухим путем. Лесной журнал. Ч. 2: 25-67.

3. Гольц Г.А. 2007. Гужевой транспорт и гужевые пути сообщения в России (исторический очерк). Россия и современный мир. 1 (54): 119-139.

4. Гребенщикова Г.А. 2004. Строительство Военно-Морского флота на Чёрном море в 30-50-е гг. ХІХ века. Дисс. ... к. и. н. СПб.: 225 с.

5. Демидов А.Н. 2018. Лашманы из служилой мордвы (по материалам переписей XVIII века). Казанское адмиралтейство (1718-1830 гг.): народы Поволжья и традиции российского судостроения. Казань: Институт истории им. Ш. Марджани АН РТ: 73-80.

6. Житков С.М. 1900. Исторический обзор устройства и содержания водных путей и портов в России за столетний период 1798-1898. СПб.: тип. Мин. путей сообщения, 264.

7. Журин Н.П. Гужевой транспорт как активная составляющая крупного сибирского города начала XX века. Балдинские чтения. 2018. Т. 13. 1: 234-237.

8. Инструкция для лесогона. 1941. Кривой рог: Криворожский дом техники, 13.

9. Ислаев Ф.Г. 2018. Происхождение и социально-экономическая эволюция лашманской деревни Подлесный Утямыш. Казанское адмиралтейство (1718-1830 гг.): народы Поволжья и традиции российского судостроения. Казань: Институт истории им. Ш. Марджани АН РТ: $104-111$.

10. Истомина Э.Г. 1982. Водные пути России во второй половине XVIII - начале XIX века. М.: Наука, 279.

11. Истомина Э.Г. 2016. Корабельные леса Европейской России как ресурс регионального развития в XVIII-XIX вв. Вестник РГГУ. Серия «История. Филология. Культурология. Востоковедение». 10: 106-119.

12. Карлсен Г.Г. 1951. Использование рабочих лошадей в колхозах. М.: Государственное издательство сельскохозяйственной литературы, 208.

13. Конорев В.В., Щерба А.Н. 2018. Транспортные проблемы вооруженной борьбы во второй половине XIX в. Клио. 10 (142): 159-162.

14. Корпачев В.П., Пережилин А.И. 2019. Оценка объемов топляковой древесины на реке Енисей на участке от Усть-Маны до Красноярска. Хвойные бореальной зоны. Т. 37. 2: 118-121.

15. Кувалдин Б.И. 1952. Из прошлого сухопутных перевозок леса в России. Лесная промышленность. 6: 14-17. 
16. Лихорадова И.Н., Мурыгин Н.Д. 2013. Формирование групп строительных рабочих и рабочих гужевого транспорта в Воронежской губернии в пореформенный период. Научный вестник Воронежского государственного архитектурно-строительного университета. Серия: Социально-гуманитарные науки. 2 (2): 18-26.

17. Мансурова Ю.В. 2010. Казанская адмиралтейская слобода в XVIII-XIX вв.: дисс... к. и. н. Казань: 231.

18. Маркс К., Энгельс Ф. 1959. К критике политической экономии. Собрание сочинений. Т. 13. М.: Политиздат, 771.

19. Стогов Э.И. 2003. Записки жандармского штаб-офицера о эпохе Николая I. М., Индрик, 239.

20. Ногманов А.И. 2008. Феномен лашманства в татарской истории. Образование и просвещение в губернской Казани: сб. ст. Казань: Институт истории им. Ш. Марджани АН РТ: $19-26$.

21. Сидякина А.Г. 2015. Функционирование внутригородского гужевого транспорта на Кубани и в Причерноморье в конце XIX - начале XX века. Культурная жизнь Юга России. 2 (57): 47-51.

22. Трошина Т.И. 2015. Проблемы развития транспортной инфраструктуры северных территорий. Материалы всероссийской научно-практической конференции. СПб., изд. ГУМ РФ им. Адм. С.О. Макарова, 2015: 207-215.

23. Фет А.А. 1863. Из деревни. Русский вестник. 1: 438-470.

24. Цейтлин М.А. 1940. Лесная промышленность крепостной России. Сдвиги в экономике и технике лесозаготовок и лесопиления крепостной России: Дис. ... канд. экон. наук. Л., 156.

25. Цейтлин М.А. 1951. К вопросу о возникновении капиталистической эксплуатации крестьян в крепостной России (государственные крестьяне на лесозаготовках). Сборник научных трудов Ленинградского финансово-экономического института. Вып. 4. Л., ЛЭФИ: 101-151.

26. Шарапов Н.И. 1958. Рационализация перевозки леса в плотах в открытых водоемах. М., Речной транспорт, 150.

27. Широкова, В.А., Снытко В.А., Чеснов В.М. и др. 2011. Вышневолоцкая водная система: ретроспектива и современность. Гидролого-экологическая обстановка и ландшафтные изменения в районе водного пути. Экспедиционные исследования: состояние, итоги, перспективы. М., ИИЕТ РАН, 246.

28. Шункова Н.О., Ушанова В.М. 2017. Основные причины экологических проблем реки Мана. Лесной и химический комплексы - проблемы и решения. Сб. материалов по итогам Всероссийской научно-практической конференции. Красноярск: СибГУ им. М.Ф. Решетнева: 374-377.

29. Ястребов Е.В. 1974. Из истории освоения лесных ресурсов Урала. Сборник трудов Московского областного педагогического института. Вопросы природных ресурсов. М., Тип. TACC: $107-115$.

30. Brush S.G. 1988. The History of Modern Science: A Guide to the Second Scientific Revolution 1800-1950. Ames: Iowa State University Press, 544.

31. Hård M., Jamison A. 1998. The Intellectual Appropriation of Technology: Discourses on Modernity, 1900-1939. Cambridge, London: MIT Press, 288.

32. Pursell C. 1995. The Machine in America: a Social History of Technology. Baltimore: Johns Hopkins University Press, 358.

\section{References}

1. Gafarov I.A. 2018. «Korabel'naya» povinnost' lashmanov Buinskogo uyezda v XVIII pervoy polovine XIX veka: nekotorye shtrikhi [«Ship» duty of lashmans of Buinskogo uyezd in the $18^{\text {th }}-$ first half of the $19^{\text {th }}$ century: some details]. Kazanskoe admiralteystvo (1718-1830 gg.): narody Povolzh'ya i traditsii rossiyskogo sudostroeniya. Kazan': Institut istorii im. Sh. Mardzhani AN RT: 51-62.

2. Gil'deman G. 1836. O dostavke lesa sukhim putem [On the delivery of woods by the land]. Lesnoy zhurnal. Part. 2: 25-67.

3. Gol'ts G.A. 2007. Guzhevoy transport i guzhevye puti soobshcheniya v Rossii (istoricheskiy ocherk) // Rossiya i sovremenniy mir. 1 (54): 119-139.

4. Grebenschikova G.A. 2004. Stroitel'stvo Voyenno-Morskogo Flota na Chyornom more [Building navy on the Black sea in 1830-50-es]. Diss. k. i. n. St. Petersburg, 225. 
5. Demidov A.N. 2018. Lashmany iz sluzhiloy mordvy (po materialam perepisey XVIII veka) [Lashmans from the serving Mordva (on the materials of enumerations of the $18^{\text {th }}$ century)]. Kazanskoe admiralteystvo (1718-1830 gg.): narody Povolzh'ya i traditsii rossiyskogo sudostroeniya. Kazan': Institut istorii im. Sh. Mardzhani AN RT: 73-80.

6. Zhitkov S.M. 1900. Istoricheskiy obzor ustroistva i soderzhaniya vodnyh putey i portov v Rossii za stoletniy period 1798-1898 [Historical survey of organizing and supporting the water ways and ports in Russia during the period 1798-1898]. St. Petersburg, tip. Min. putej soobshheniya, 264.

7. Zhurin N.P. Guzhevoy transport kak aktivnaya sostavlyayushchaya krupnogo sibirskogo goroda nachala XX veka [Horse-drawn transport as an active part of big Siberian city in the beginning of the $20^{\text {th }}$ century]. Baldinskie chteniya. 2018. T.13. 1: 234-237.

8. Instrukciya dlya lesogona [Wood-driver's instruction]. 1941. Krivoy rog, Krivorozhskij dom tehniki, 13.

9. Islaev F.G. 2018. Proishozhdenie i social'no-ekonomicheskaja evoluciya lashmanskoy derevni Podlesnyy Utiamysh [The origin and social-economical evolution of lashmen's village Podlesnyy Utiamysh]. Kazanskoe admiraltejstvo (1718-1830 gg.): narody Povolzh'ja i tradicii rossiyskogo sudostroenija. Kazan', Institut istorii im. Sh. Mardzhani AN RT, 104-111.

10. Istomina E.G. 1982. Vodnye puti Rossii vo vtoroi polovine XVIII - nachale XIX veka [Water communications of Russia in the second half of the $18^{\text {th }}$ - early $19^{\text {th }}$ centuries]. Moscow, Nauka, 279.

11. Istomina E.G. 2016. Korabel'nye lesa Evropejskoy Rossii kak resurs regional'nogo razvitiya v XVIII-XIX vv. [Naval woods of European Russia as a resource of regional development in the $18-19^{\text {th }}$ centuries]. Vestnik RGGU. Serija «Istorija. Filologija. Kul'turologija. Vostokovedenie». 10: 106-119.

12. Karlsen G.G. 1951. Ispol'zovanie rabochih loshadei v kolkhozakh [The usage of working horses at the collective farms]. Mowcow: Gosudarstvennoe izdatel'stvo sel'skohoziaystvennoy literatury, 208.

13. Konorev V.V., Shcherba A.N. 2018. Transportnye problemy vooruzhennoy bor'by vo vtoroy polovine XIX v. [Transport problems of military struggle in the second half of the $19^{\text {th }}$ century] Clio. 10 (142): 159-162.

14. Korpachev V.P., Perezhilin A.I. 2019. Otcenka ob'emov topliakovoy drevesiny na reke Enisey na uchastke ot Ust'-Many do Krasnoyarska [The estimation of drawn woods in the rivers Yenisei from Ust'-Many to Krasnoyarsk]. Hvoynye boreal'noy zony, T. 37, 2: 118-121.

15. Kuvaldin B.I. 1952. Iz proshlogo sukhoputnykh perevozok lesa v Rossii [From the past of wood horse-drawn transportation in Russia]. Lesnaya promyshlennost'. 6: 14-17.

16. Likhoradova I.N., Murygin N.D. 2013. Formirovanie grupp stroitel'nykh rabochikh i rabochikh guzhevogo transporta $\mathrm{v}$ Voronezhskoy gubernii $\mathrm{v}$ poreformenniy period [The formation of group of workers and workers of horse-drawn transport]. Nauchniy vestnik Voronezhskogo gosudarstvennogo arkhitekturno-stroitel'nogo universiteta. Seriya: Sotsial'no-gumanitarnye nauki. 2 (2): $18-26$.

17. Mansurova Yu.V. 2010. Kazanskaya admiralteyskaya sloboda v XVIII-XIX vv. [Admiralty village of Kazan']: diss... k. i. n. Kazan': 231.

18. Marx K., Yengel's F. 1959. K kritike politicheskoy ekonomii [To the critics of political ecomony]. Sobranie sochineniy. T. 13. Moscow, Politizdat: 1-167.

19. Nogmanov A.I. 2008. Fenomen lashmanstva $v$ tatarskoy istorii [The phenomenon of lashmanstvo in the history of Tatars]. Obrazovanie i prosveshchenie v gubernskoy Kazani: sb. st. Kazan': Institut istorii im. Sh. Mardzhani AN RT: 19-26.

20. Sidyakina A.G. 2015. Funktsionirovanie vnutrigorodskogo guzhevogo transporta na Kubani i v Prichernomor'e v kontse XIX - nachale XX veka [Functioning of internal horse-drawn transport at Kuban' and Black sea region in the late $19^{\text {th }}-$ early $20^{\text {th }}$ century]. Kul'turnaya zhizn' Yuga Rossii. 2 (57): $47-51$

21. Stogov Ye.I. 2003. Zapiski zhandarmskogo shtab-oficera o epokhe Nikolaya I [The notes of police-officer on the epoch of Nicolas $1^{\text {st }}$. Moscow, Indrik, 239.

22. Troshina T.I. 2015. Problemy razvitiya transportnoy infrastruktury severnykh territoriy [Problems of development of transport in the North]. Materialy vserossiyskoy nauchno-prakticheskoy konferentsii. St. Petersburg.: izd. GUM RF im. Adm. S.O. Makarova: 207-215.

23. Fet A.A. 1863. Iz derevni [From the village]. Russkiy vestnik. 1: 438-470. 
24. Tseytlin M.A. 1940. Lesnaya promyshlennost' krepostnoy Rossii. Sdvigi v ekonomike i tekhnike lesozagotovok i lesopileniya krepostnoy Rossii [Wood industry in serf-time Russia. Economy and technical shifts in wood industry of serf-time Russia]: Dis. ... kand. ekon. nauk. Leningrad: 156.

25. Tseitlin M.A. 1951. K voprosu o vozniknovenii kapitalisticheskoy ekspluatacii krest'jan v krepostnoy Rossii (Gosudarstvennye krest'yane na lesozagotovkah) [To the problem of the appearance of the capitalistic exploitation of peasants in Russia (state peasants on wood-cuttings)]. Sbornik nauchnyh trudov Leningradskogo finansovo-jekonomicheskogo instituta. Vyp. 4. Leningrad, LJeFI, 101-151.

26. Sharapov N.I. 1958. Ratcionalizaciya perevozki lesa $\mathrm{v}$ plotah $\mathrm{v}$ otkrytyh vodoemah [Rationalization of wood transportation in rafts in the open water]. Moscow, Rechnoj transport, 150.

27. Shirokova, V.A., Snytko V.A., Chesnov V.M. i dr. 2011. Vyshnevolockaja vodnaya sistema: retrospektiva i sovremennost'. Gidrologo-ekologicheskaya obstanovka i landshaftnye izmeneniya v raione vodnogo puti. Ekspedicionnye issledovaniya: sostoyaniye, itogi, perspektivy [The water system of Vyshniy Volochk: retrospective and modernity. Hydro-ecological research: modern state, recults, perspectives]. Moscow, IIET RAN, 246.

28. Shunkova N.O., Ushanova V.M. 2017. Osnovnye prichiny ekologicheskikh problem reki Mana [Basic principles of ecological problems of the Mana river]. Lesnoy i himicheskiy kompleksy problemy i reshenija. Sb. materialov po itogam Vserossijskoj nauchno-prakticheskoj konferencii. Krasnojarsk, SibGU im. M.F. Reshetneva: 374-377.

29. Yastrebov E.V. 1974. Iz istorii osvoeniya lesnyh resursov Urala [From the history of reclaiming of the forest resources at Ural]. Sbornik trudov Moskovskogo oblastnogo pedagogicheskogo instituta. Voprosy prirodnyh resursov. Moscow, Tip. TASS, 107-115.

30. Brush S.G. 1988. The History of Modern Science: A Guide to the Second Scientific Revolution 1800-1950. Ames: Iowa State University Press, 544.

31. Hård M., Jamison A. 1998. The Intellectual Appropriation of Technology: Discourses on Modernity, 1900-1939. Cambridge, London: MIT Press, 288.

32. Pursell C. 1995. The Machine in America: a Social History of Technology. Baltimore: Johns Hopkins University Press, 358.

Конфликт интересов: о потенциальном конфликте интересов не сообщалось.

Conflict of interest: no potential conflict of interest related to this article was reported.

\section{ИНФОРМАЦИЯ ОБ АВТОРЕ}

Евгения Михайловна Лупанова, кандидат исторических наук, старший научный сотрудник отдела Музея антропологии и этнографии им. Петра Великого РАН (Кунсткамера), СанктПетербург, Россия

\section{INFORMATION ABOUT THE AUTHOR}

Yevgenia M. Lupanova, candidate of Historical Sciences, Senior Researcher of the Department of the Museum of Anthropology and Ethnography. Peter the Great RAS (Kunstkamera), St. Petersburg, Russia 